\title{
HUBUNGAN PEMBERIAN ASI EKSKLUSIF DENGAN STATUS GIZI BADUTA USIA 6-24 BULAN DI DESA TIMBUSENG KABUPATEN GOWA
}

\section{THE CORRELATIONS EXCLUSIVE BREASTFEEDING WITH NUTRITIONAL STATUS OF CHILDREN AGES 6-24 MONTHS IN TIMBUSENG VILLAGE DISTRICT GOWA}

\author{
Nur Annisa Hamid ${ }^{1}$, Veni Hadju ${ }^{1}$, Djunaidi M Dachlan ${ }^{1}$ Nurhaedar Jafar $^{1}$, Sabaria \\ Manti Battung ${ }^{1}$ \\ (Email/HP : nurannisahamid29@gmail.com/ 087849591237)
}

Program Studi Ilmu Gizi Fakultas Kesehatan Masyarakat Universitas Hasanuddin

\begin{abstract}
ABSTRAK
Pendahuluan: Gizi sangat berperan dalam tumbuh kembang anak. Tujuan pemberian gizi yang baik adalah mencapai tumbuh kembang anak yang adekuat. Pada bayi dan anak, kekurangan gizi akan menimbulkan gangguan pertumbuhan dan perkembangan yang apabila tidak diatasi secara dini akan berlanjut hingga dewasa. Tujuan: Penelitian ini bertujuan untuk mengetahui hubungan pemberian Air Susu Ibu Eksklusif dengan status gizi baduta usia 6-24 bulan. Metode: Jenis penelitian penelitian yang digunakan adalah oservasional analitik dengan menggunakan rancangan penelitian cross sectional dengan jumlah sampel yang didapatkan sebanyak 108 anak. Hasil: Hasil penelitian menunjukkan bahwa tidak terdapat hubungan antara pemberian ASI Eksklusif dengan status gizi berdasarkan Berat Badan Menurut Umur $(p=0,457)$, tidak terdapat hubungan antara pemberian ASI Eksklusif dengan status gizi berdasarkan Panjang Badan Menurut Umur $(p=0,929)$, dan terdapat hubungan pemberian ASI Eksklusif dengan status gizi Berdasarkan Berat Badan Menurut Panjang Badan ( $p=0,041)$. Kesimpulan: Pemberian ASI Eksklusif memiliki hubungan dengan status gizi baduta berdasarkan indikator berat badan menurut panjang badan (BB/PB) tetapi tidak demikian untuk status gizi berdasarkan indikator berat badan menurut umur $(\mathrm{BB} / \mathrm{U})$ serta panjang badan menurut umur $(\mathrm{PB} / \mathrm{U})$.
\end{abstract}

\section{Kata Kunci : Baduta Usia 6-24 Bulan, ASI Ekslusif, Status Gizi}

\section{ABSTRACT}

Nutrition plays very important role in the growth and development of children. Giving good nutrition is aim to reach the adequate child growth and development. For infants and children, malnutrition will affect their growth and development, in which if it cannot be resolved earlier, then it Will be continued until they are adult. The purpose of this research is to know the relationship between Exclusive breastfeeding with nutritional status of babies aged 6-24 months. The type of this research is analytic Observational by using a cross sectional study design with a sample of 108 children. The results showed that there was no relationship between exclusive breastfeeding with nutritional status based on body weight according to age $(p=0.457)$, there was no relationship between exclusive breastfeeding with nutritional status at body length according to age $(p=0.929)$, and the assistance relationship was available Exclusive breastfeeding with nutritional status based on body weight according to body length $(p=0.041)$. Exclusive breastfeeding has a relationship with the nutritional status of under two years based on indicators of body weight according to body length but this is not the case for nutritional status based on weight indicators according to age and body length according to age. 


\section{Keywords : Children 6 to 24 month, Exclusive Breastfeeding, Nutritional Status}

\section{PENDAHULUAN}

Air Susu Ibu (ASI) memiliki banyak sekali manfaat bagi bayi. Pemberian ASI yang optimal merupakan kegiatan penting dalam pemeliharaan anak dan persiapan generasi penerus yang berkualitas di masa depan. ${ }^{1}$ Pertumbuhan dan perkembangan bayi dipengaruhi oleh jumlah zat gizi yang dikonsumsi. Kebutuhan zat gizi ini sebagian besar dapat terpenuhi dengan pemberian ASI yang cukup. ASI tidak hanya sebagai sumber energi utama tapi juga sebagai sumber protein, vitamin dan mineral utama bagi bayi. ${ }^{1}$ Terjadinya kerawanan gizi pada bayi disebabkan makanan yang kurang serta penggantian ASI dengan susu botol dengan cara dan jumlah yang tidak memenuhi kebutuhan. ${ }^{2}$

Banyak penelitian yang telah membuktikan bahwa ASI penting untuk tumbuh kembang optimal bayi. Salah satu jurnal yang melakukan penelitian tersebut adalah penelitian dari Sofyana yang menyatakan bahwa rata-rata perubahan panjang badan neonatus selama 1 bulan (28 hari) pada neonatus yang diberikan ASI eksklusif sebesar $1,078 \mathrm{~cm}$, sedangkan neonatus yang diberikan non eksklusif sebesar $1,008 \mathrm{~cm}$. Lebih lanjut hasil penelitian menunjukkan bahwa pada balita baduta usia 6-24 bulan yang tidak ASI eksklusif lebih banyak mengalami stunting sebesar 30,7\%, dibandingkan dengan balita baduta yang mendapatkan ASI eksklusif hanya $11,1 \%$ stunting. Sebaliknya bayi yang mendapat ASI eksklusif lebih banyak yang mempunyai status gizi (TB/U) normal $(88,9 \%)$ dibandingkan balita baduta yang tidak eksklusif $(69,3 \%)$. Hasil ini menunjukkan ada kecenderungan balita yang tidak diberi ASI eksklusif lebih tinggi proporsi stunting. Lebih lanjut hasil penelitian Susanty mendukung bahwa lama menyusui, berhubungan signifikan dengan kejadian gizi buruk . ${ }^{3}$

Program Peningkatan Pemberian ASI (PP-ASI) khususnya ASI eksklusif mempunyai dampak yang luas terhadap status gizi ibu dan bayi. Pemberian ASI di Indonesia belum dilaksanakan sepenuhnya. Upaya meningkatkan perilaku menyusui pada ibu yang memiliki bayi khususnya ASI eksklusif masih dirasa kurang. Permasalahan utama adalah faktor sosial budaya, kesadaran tentang pentingnya ASI, pelayanan kesehatan dan petugas kesehatan yang belum sepenuhnya mendukung PP-ASI, gencarnya promosi susu formula dan ibu bekerja . ${ }^{4}$

Hasil Riset Kesehatan Dasar (Riskesdas) tahun 2018 menunjukkan bahwa persentase gizi buruk pada balita usia 0-23 bulan di Indonesia adalah 3,8\%, sedangkan persentase gizi kurang adalah $11,4 \%$. Selanjutnya persentase balita sangat pendek dan pendek usia 0-23 bulan di Indonesia tahun 2018 yaitu 12,8\% dan 17,1\%. Persentase balita sangat kurus dan kurus usia 0-23 bulan di Indonesia pada tahun 2018 adalah 4,5\% dan 7,2\%. ${ }^{5}$

Secara nasional, cakupan bayi mendapat ASI eksklusif tahun 2018 yaitu sebesar 68,74\%. Angka tersebut sudah melampaui target Renstra tahun 2018 yaitu 47\%. Persentase tertinggi cakupan pemberian ASI eksklusif terdapat pada Provinsi Jawa Barat (90,79\%), sedangkan persentase terendah terdapat di Provinsi Gorontalo (30,71\%). ${ }^{6}$ Berdasarkan Profil Kesehatan Provinsi Sulawesi Selatan 2016, jumlah bayi yang diberi ASI Eksklusif hanya sekitar 59,14\% saja. ${ }^{7}$ Oleh karena itu perlu kita pikirkan untuk status gizi kedepan agar anak dari setiap ibu tetap mendapatkan ASI eksklusif dan MP ASI serta pola asuh orang tua yang memegang peran penting dalam proses tumbuh kembang anak. Berdasarkan uraian tersebut maka penulis mencoba untuk meneliti permasalahan ini untuk mengetahui hubungan pemberian ASI 
eksklusif terhadap status gizi bayi usia 6-24 bulan di Desa Timbuseng Kecamatan Pattallassang Kabupaten Gowa.

\section{BAHAN DAN METODE}

Penelitian ini dilakukan di Desa Timbuseng Kecamatan Patttallassang Kaupaten Gowa. Jenis penelitian ini adalah penelitian obserasional analitik dengan rancangan cross sectional. Populasi dalam penelitian ini adalah seluruh bayi usia 6-24 bulan yang berdomisili di Desa Timbuseng Kecamatan Pattallassang Kabupaten Gowa yang berjumlah 147 orang. Jumlah sampel dalam penelitian ini yaitu 108 bayi usia 6-24 bulan dengan menggunakan teknik sampling aksidental.

Data sekunder diperoleh dari puskesmas terkait seperti jumlah balita usia 6-24 bulan serta data data berupa gambaran umum lokasi di ambil di kantor Desa Timbuseng. Untuk indeks status gizi yang digunakan yaitu $\mathrm{BB} / \mathrm{U}, \mathrm{PB} / \mathrm{U}$ dan $\mathrm{BB} / \mathrm{PB}$. Untuk $\mathrm{BB} / \mathrm{U}$ yang dimana kategorinya yaitu gizi buruk dengan nilai Z-score $<-3 \mathrm{SD}$, gizi kurang dengan nilai Z-score 3 SD sampai dengan <-2 SD, gizi baik dengan nilai Z-score -2 SD sampai dengan >2 SD, dan gizi lebih dengan nilai Z-score $>2 \mathrm{SD}$. Untuk indeks $\mathrm{PB} / \mathrm{U}$ yang dimana kategorinya yaitu sangat pendek dengan nilai Z-score <-3 SD, pendek dengan nilai Z-score -3 SD sampai dengan $<-2 \mathrm{SD}$, normal dengan nilai Z-score -2 SD sampai dengan $>2 \mathrm{SD}$, dan tinggi dengan nilai Z-score $>2 \mathrm{SD}$. Untuk BB/PB yang dimana kategorinya yaitu sangat kurus dengan nilai Z-score <-3 SD, kurus dengan nilai Z-score -3 SD sampai dengan <-2 SD, normal dengan nilai Z-score $-2 \mathrm{SD}$ sampai dengan $>2 \mathrm{SD}$, dan gemuk dengan nilai Z-score $>2 \mathrm{SD}$. Data yang telah dikumpul diolah menggunakan SPSS 24.0. Untuk melihat hubungan pemberian ASI Eksklusif dengan status gizi bayi usia 6-24 bulan digunakan analisi univariat dan analisis bivariat dengan melakukan uji Chi-Square.

\section{HASIL}

Berdasarkan Tabel 1 diketahui bahwa sampel terbanyak berdasarkan jenis kelamin yaitu bayi perempuan $(58,3 \%)$ dan bayi laki-laki sebanyak $42,7 \%$. Baduta dengan Berat Badan Lahir Rendah sebanyak 4,6\%, sedangkan baduta dengan Berat Badan Lahir Normal sebanyak $95,4 \%$. Baduta dengan panjang badan lahir $<48 \mathrm{~cm}$ sebanyak 29,6\%, sedangkan baduta dengan panjang lahir $\geq 48 \mathrm{~cm}$ sebanyak $70,4 \%$.

Untuk tempat persalinan, paling banyak di Fasilitas Pelayanan Kesehatan (Fasyankes) sebanyak 98,1\% dan paling sedikit tidak di Fasilitas Pelayanan Kesehatan (Fasyankes) sebanyak $1,9 \%$. Untuk penolong persalinan, paling banyak pada bidan sebanyak $88,9 \%$ dan paling sedikit pada dukun sebanyak $0,9 \%$. Ibu yang melakukan Inisiasi Menyusui Dini sebanyak 70,4\%, dan yang memberikan kolostrum kepada bayinya sebanyak 97,2\%. Ibu yang memberikan ASI Eksklusif sebanyak 65,7\%. Ibu yang menyusui bayinya $<8$ kali sehari sebanding dengan ibu yang menyusui bayinya $<15$ menit sehari sebanyak $16,7 \%$, begitu pula dengan ibu yang menyusui bayinya $\geq 8$ kali sehari sebanding dengan ibu yang menyusui bayinya $\geq 15$ menit sehari sebanyak $83,3 \%$. Sebagian besar baduta yang pernah mengalami diare sebanyak $78,7 \%$ dan yang mendapatkan imunisasi lengkap sebesar $62 \%$. Berdasarkan umur sampel lebih banyak pada kelompok umur 13-24 bulan $(61,1 \%)$ dan paling sedikit adalah pada kelompok umur 6-12 bulan $(38,9 \%)$. 
Tabel 1. Distribusi Karakteristik Baduta di Desa Timbuseng Kecamatan Pattallassang Kabupaten Gowa Tahun 2020

\begin{tabular}{|c|c|c|}
\hline Karakteristik & $\mathbf{n}$ & $(\%)$ \\
\hline \multicolumn{3}{|l|}{ Jenis Kelamin } \\
\hline Laki-laki & 45 & 41,7 \\
\hline Perempuan & 63 & 58,3 \\
\hline \multicolumn{3}{|l|}{ Berat Badan Lahir } \\
\hline Rendah & 5 & 4,6 \\
\hline Normal & 103 & 95,4 \\
\hline \multicolumn{3}{|l|}{ Panjang Badan Lahir } \\
\hline$<48 \mathrm{~cm}$ & 32 & 29,6 \\
\hline$\geq 48 \mathrm{~cm}$ & 76 & 70,4 \\
\hline \multicolumn{3}{|l|}{ Tempat Persalinan } \\
\hline Di Fasyankes & 106 & 98,1 \\
\hline Tidak di Fasyankes & 2 & 1,9 \\
\hline \multicolumn{3}{|l|}{ Penolong Persalinan } \\
\hline Dokter Kandungan & 11 & 10,2 \\
\hline Bidan & 96 & 88,9 \\
\hline Dukun & 1 & 0,9 \\
\hline \multicolumn{3}{|l|}{ Melakukan IMD } \\
\hline $\mathrm{Ya}$ & 76 & 70,4 \\
\hline Tidak & 32 & 29,6 \\
\hline \multicolumn{3}{|l|}{ Pemberian Kolostrum } \\
\hline $\mathrm{Ya}$ & 105 & 97,2 \\
\hline Tidak & 3 & 2,8 \\
\hline \multicolumn{3}{|l|}{ ASI Eksklusif } \\
\hline $\mathrm{Ya}$ & 71 & 65,7 \\
\hline Tidak & 37 & 34,3 \\
\hline \multicolumn{3}{|l|}{ Frekuensi Menyusui } \\
\hline$<8$ kali sehari & 18 & 16,7 \\
\hline$\geq 8$ kali sehari & 90 & 83,3 \\
\hline \multicolumn{3}{|l|}{ Lama Menyusui } \\
\hline$<15$ menit sehari & 18 & 16,7 \\
\hline$\geq 15$ menit sehari & 90 & 83,3 \\
\hline \multicolumn{3}{|l|}{ Riwayat Diare } \\
\hline Ya & 85 & 78,7 \\
\hline Tidak & 23 & 21,3 \\
\hline \multicolumn{3}{|l|}{ Pernah Imunisasi } \\
\hline $\mathrm{Ya}$ & 103 & 95,4 \\
\hline Tidak & 5 & 4,6 \\
\hline \multicolumn{3}{|l|}{ Imunisasi Lengkap } \\
\hline Ya & 67 & 62 \\
\hline Tidak & 41 & 38 \\
\hline \multicolumn{3}{|l|}{ Umur Bayi } \\
\hline $6-12$ & 42 & 38,9 \\
\hline $13-24$ & 66 & 61,1 \\
\hline
\end{tabular}

Sumber: Data Primer, 2020 
Tabel 2. Distribusi Karakteristik Orang Tua Baduta di Desa Timbuseng Kecamatan Pattallassang Kabupaten Gowa Tahun 2020

\begin{tabular}{|c|c|c|}
\hline Karakteristik & $\mathbf{n}$ & $(\%)$ \\
\hline \multicolumn{3}{|l|}{ Umur Ayah } \\
\hline$<21$ & 3 & 2,8 \\
\hline $21-30$ & 39 & 36,1 \\
\hline $31-40$ & 54 & 50,0 \\
\hline$>40$ & 12 & 11,1 \\
\hline \multicolumn{3}{|l|}{ Umur Ibu } \\
\hline$<21$ & 7 & 6,5 \\
\hline $21-30$ & 58 & 53,7 \\
\hline $31-40$ & 39 & 36,1 \\
\hline$>40$ & 4 & 3,7 \\
\hline \multicolumn{3}{|l|}{ Pendidikan Ayah } \\
\hline Tidak tamat SD/MI & 7 & 6,5 \\
\hline Tamat SD/MI & 35 & 32,4 \\
\hline Tamat SMP/MTs & 12 & 11,1 \\
\hline Tamat SMA/MA & 49 & 45,4 \\
\hline Tamat PT & 5 & 4,6 \\
\hline \multicolumn{3}{|l|}{ Pendidikan Ibu } \\
\hline Tidak tamat SD/MI & 4 & 3,7 \\
\hline Tamat SD/MI & 41 & 38 \\
\hline Tamat SMP/MTs & 23 & 21,3 \\
\hline Tamat SMA/MA & 26 & 24,1 \\
\hline Tamat PT & 14 & 12,9 \\
\hline \multicolumn{3}{|l|}{ Pekerjaan Ayah } \\
\hline Tidak Bekerja & 1 & 0,9 \\
\hline Pegawai Swasta & 10 & 9,3 \\
\hline Wiraswasta & 31 & 28,7 \\
\hline Petani/Buruh Tani & 28 & 25,9 \\
\hline Buruh & 33 & 30,6 \\
\hline Lainnya & 5 & 4,6 \\
\hline \multicolumn{3}{|l|}{ Pekerjaan Ibu } \\
\hline IRT & 100 & 92,6 \\
\hline Pegawai Swasta & 1 & 0,9 \\
\hline Wiraswasta & 2 & 1,9 \\
\hline Lainnya & 5 & 4,6 \\
\hline \multicolumn{3}{|l|}{ Pendapatan } \\
\hline$\leq \mathrm{Rp} .1 .000 .000$ & 9 & 8,3 \\
\hline Rp.1.000.001-Rp.2.000.000 & 32 & 29,6 \\
\hline Rp.2.000.001-Rp.3.000.000 & 45 & 41,7 \\
\hline >Rp.3.000.000 & 22 & 20,4 \\
\hline
\end{tabular}

Sumber: Data Primer, 2020

Hasil penelitian menunjukkan bahwa umur ayah paling banyak yaitu pada kategori umur 31-40 tahun sebanyak 50\% sedangkan paling sedikit yaitu pada kategori di bawah 21 tahun sebanyak 2,8\%. Untuk umur ibu paling banyak yaitu pada kategori umur 21-30 tahun sebanyak 53,7\% sedangkan paling sedikit yaitu pada kategori umur di atas 40 tahun 3,7\%. Untuk pendidikan terakhir ayah paling banyak yaitu tamat SMA $(45,5 \%)$ sedangkan paling 
sedikit yaitu tamat PT $(4,6 \%)$. Untuk pendidikan terakhir ibu paling banyak yaitu tamat SD (38\%) sedangkan paling sedikit yaitu tidak tamat SD (3,7\%). Untuk pekerjaan ayah paling banyak yaitu buruh $(30,6 \%)$ dan paling sedikit yaitu tidak bekerja $(0,9 \%)$. Untuk pekerjaan ibu paling banyak yaitu ibu rumah tangga $(92,6 \%)$ sedangkan paling sedikit yaitu pegawai swasta $(0,9 \%)$. Untuk pendapatan keluarga paling banyak pada kategori Rp.2.000.001Rp.3.000.000 (41,7\%) sedangkan paling sedikit pada kategori $\leq$ Rp.1.000.000 (8,3\%).

Tabel 3. Distribusi Frekuensi Status Gizi Berdasarkan Berat Badan Menurut Umur, Panjang Badan Menurut Umur, dan Berat Badan Menurut Panjang Badan, di Desa Timbuseng Kecamatan Pattallassang Kabupaten Gowa Tahun 2020

\begin{tabular}{lcc}
\hline \multicolumn{1}{c}{ Variabel } & n & Baduta \\
\cline { 2 - 3 } & & \% \\
\hline Berat Badan Menurut Umur (BB/U) & 6 & 5,6 \\
Gizi Buruk & 25 & 23,1 \\
Gizi Kurang & 77 & 71,3 \\
Gizi Baik & & \\
\hline Panjang Badan Menurut Umur (PB/U) & 21 & 19,4 \\
Sangat Pendek & 21 & 19,4 \\
Pendek & 63 & 58,3 \\
Normal & 3 & 2,8 \\
Tinggi & & \\
\hline Berat Badan Menurut Panjang Badan & & 5,6 \\
(BB/PB) & 6 & 11,1 \\
Sangat Kurus & 12 & 79,6 \\
Kurus & 86 & 3,7 \\
Normal & 4 & \\
Gemuk & & \\
\hline Sumber: Data Primer 2020 & & \\
\end{tabular}

Sumber: Data Primer, 2020

Tabel 4. Hubungan Pemberian ASI Eksklusif dengan Berat Badan Menurut Umur $(B B / U)$ di Desa Timbuseng Kecamatan Pattallassang Kabupaten Gowa Tahun 2020

\begin{tabular}{|c|c|c|c|c|c|c|c|c|c|}
\hline \multirow{3}{*}{ ASI Eksklusif } & \multicolumn{6}{|c|}{ Berat Badan Menurut Umur } & \multirow{2}{*}{\multicolumn{2}{|c|}{ Total }} & \multirow{3}{*}{$p$} \\
\hline & \multicolumn{2}{|c|}{ Gizi Buruk } & \multicolumn{2}{|c|}{ Gizi Kurang } & \multicolumn{2}{|c|}{ Gizi Baik } & & & \\
\hline & n & $\%$ & $\mathbf{n}$ & $\%$ & $\mathbf{n}$ & $\%$ & $\mathbf{n}$ & $\%$ & \\
\hline $\mathrm{Ya}$ & 4 & 5,6 & 19 & 26,8 & 48 & 67,6 & 71 & 100 & \\
\hline Tidak & 2 & 5,4 & 6 & 16,2 & 29 & 78,4 & 37 & 100 & 0,457 \\
\hline Total & 6 & 5,6 & 25 & 23,1 & 77 & 71,3 & 108 & 100 & \\
\hline
\end{tabular}

Sumber : Data Primer, 2020

Persentase status gizi berdasarkan Berat Badan Menurut Umur paling banyak pada kategori gizi baik yaitu sebanyak $71,3 \%$ dan yang paling sedikit pada kategori gizi buruk yaitu sebanyak 5,6\%. Untuk persentase status gizi berdasarkan Panjang Badan Menurut Umur paling banyak pada kategori gizi normal yaitu sebanyak $58,3 \%$ dan yang paling sedikit pada kategori tinggi yaitu sebanyak 2,8\%. Untuk persentase status gizi berdasarkan Berat 
Badan Menurut Panjang Badan paling banyak pada kategori normal yaitu sebanyak 79,6\% dan paling sedikit pada kategori gemuk yaitu sebanyak 3,7\%.

Berdasarkan Pemberian ASI Eksklusif, anak yang mendapat ASI Eksklusif selama 6 bulan berdasarkan Berat Badan Menurut Umur persentase tertinggi pada kategori gizi baik yaitu sebanyak $67,6 \%$ dan persentase terendah pada kategori gizi buruk yaitu sebanyak 5,6\%, sedangkan anak yang tidak mendapat ASI Eksklusif 6 bulan presentase tertinggi pada kategori gizi baik yaitu sebanyak $78,4 \%$ dan persentase terendah pada kategori gizi buruk yaitu sebanyak 5,4\% Berdasarkan hasil uji statistik Chi-Square diperoleh nilai p-value = $0,475$ ( $p>0,05)$ yang berarti tidak terdapat hubungan antara ASI Eksklusif dengan Berat Badan Menurut Umur (BB/U), sehingga dapat disimpulkan Ho diterima, tidak ada hubungan antara ASI Eksklusif dengan Berat Badan Menurut Umur (BB/U).

Tabel 5. Hubungan Pemberian ASI Eksklusif dengan Panjang Badan Menurut Umur $(\mathrm{PB} / \mathrm{U})$ di Desa Timbuseng Kecamatan Pattallassang Kabupaten Gowa Tahun 2020

\begin{tabular}{|c|c|c|c|c|c|c|c|c|c|c|c|}
\hline \multirow{3}{*}{ ASI Eksklusif } & \multicolumn{8}{|c|}{ Panjang Badan Menurut Umur } & \multirow{2}{*}{\multicolumn{2}{|c|}{ Total }} & \multirow{3}{*}{$p$} \\
\hline & \multicolumn{2}{|c|}{ Sangat Pendek } & \multicolumn{2}{|c|}{ Pendek } & \multicolumn{2}{|c|}{ Normal } & \multicolumn{2}{|c|}{ Tinggi } & & & \\
\hline & $\mathbf{n}$ & $\%$ & $\mathbf{n}$ & $\%$ & $\mathbf{n}$ & $\%$ & $\mathbf{n}$ & $\%$ & $\mathbf{n}$ & $\%$ & \\
\hline Ya & 15 & 21,1 & 13 & 18,3 & 41 & 57,8 & 2 & 2,8 & 71 & 100 & \\
\hline Tidak & 6 & 16,2 & 8 & 21,6 & 22 & 59,5 & 1 & 2,7 & 37 & 100 & 0,929 \\
\hline Total & 21 & 19,4 & 21 & 19,4 & 63 & 58,3 & 3 & 2,8 & 108 & 100 & \\
\hline
\end{tabular}

Sumber : Data Primer, 2020

Berdasarkan Pemberian ASI Eksklusif, anak yang mendapat ASI Eksklusif selama 6 bulan berdasarkan Panjang Badan Menurut Umur persentase tertinggi pada kategori normal yaitu sebanyak $57,8 \%$ dan persentase terendah pada kategori tinggi yaitu sebanyak 2,8\% sedangkan anak yang tidak mendapat ASI Eksklusif selama 6 bulan presentase tertinggi pada kategori normal yaitu sebanyak 59,5\% dan persentase terendah pada kategori tinggi yaitu sebanyak 2,7\% . Berdasarkan hasil uji statistik Chi-Square diperoleh nilai p-value $=0,929$ $(p>0,05)$ yang berarti tidak terdapat hubungan antara ASI Eksklusif dengan Panjang Badan Menurut Umur (PB/U), sehingga dapat disimpulkan Ho diterima, tidak ada hubugan antara ASI Eksklusif dengan Panjang Badan Menurut Umur (PB/U).

Tabel 6. Hubungan Pemberian ASI Eksklusif dengan Berat Badan Menurut Panjang Badan (BB/PB) di Desa Timbuseng Kecamatan Pattallassang Kabupaten Gowa Tahun 2020

\begin{tabular}{|c|c|c|c|c|c|c|c|c|c|c|c|}
\hline \multirow{3}{*}{ ASI Eksklusif } & \multicolumn{8}{|c|}{ Berat Badan Menurut Panjang Badan } & \multirow{2}{*}{\multicolumn{2}{|c|}{ Total }} & \multirow{3}{*}{$p$} \\
\hline & \multicolumn{2}{|c|}{ Sangat Kurus } & \multicolumn{2}{|c|}{ Kurus } & \multicolumn{2}{|c|}{ Normal } & \multicolumn{2}{|c|}{ Gemuk } & & & \\
\hline & $\mathbf{n}$ & $\%$ & $\mathbf{n}$ & $\%$ & $\mathbf{n}$ & $\%$ & $\mathbf{n}$ & $\%$ & n & $\%$ & \\
\hline Ya & 4 & 5,6 & 9 & 12,7 & 58 & 81,7 & 0 & 0 & 71 & 100 & \\
\hline Tidak & 2 & 5,4 & 3 & 8,1 & 28 & 75,7 & 4 & 10,8 & 37 & 100 & \\
\hline Total & 6 & 5,6 & 12 & 11,1 & 86 & 79,6 & 4 & 3,7 & 108 & 100 & \\
\hline
\end{tabular}

Sumber : Data Primer, 2020

Berdasarkan Pemberian ASI Eksklusif, anak yang mendapat ASI Eksklusif selama 6 bulan berdasarkan Berat Badan Menurut Panjang Badan persentase tertinggi pada kategori normal yaitu sebanyak $81,7 \%$ dan persentase terendah pada kategori sangat kurus yaitu sebanyak 4\% sedangkan anak yang tidak mendapat ASI Eksklusif selama 6 bulan presentase 
tertinggi pada kategori normal yaitu sebanyak 75,7\% dan persentase terendah pada kategori sangat kurus yaitu sebanyak 5,4\%. Berdasarkan hasil uji statistik Chi-Square diperoleh nilai $\mathrm{p}$-value $=0,041(p<0,05)$ yang berarti terdapat hubungan antara ASI Eksklusif dengan Berat Badan Menurut Panjang Badan (BB/PB), sehingga dapat disimpulkan Ho ditolak, ada hubugan antara ASI Eksklusif dengan Panjang Badan Menurut Umur (BB/PB).

\section{PEMBAHASAN}

\section{Hubungan Pemberian ASI Eksklusif dengan Berat Badan Menurut Umur (BB/U)}

Berdasarkan hasil penelitian yang tertera pada Tabel 5 menunjukkan bahwa dari 71 baduta yang mendapatkan ASI Eksklusif, terdapat 4 baduta $(5,6 \%)$ yang berstatus gizi buruk, 19 baduta $(26,8 \%)$ yang berstatus gizi kurang, dan 48 baduta $(67,6 \%)$ yang berstatus gizi baik. Sedangkan yang tidak mendapatkan ASI Eksklusif sebanyak 37 baduta. Terdapat 2 baduta $(5,4 \%)$ yang berstatus gizi buruk, 6 baduta $(16,2 \%)$ yang berstatus gizi kurang, dan 29 baduta $(78,4 \%)$ berstatus gizi baik. Berdasarkan hasil uji statistik Chi-Square diperoleh nilai p-value $=0,475(p<0,05)$ yang berarti tidak terdapat hubungan antara ASI Eksklusif dengan Berat Badan Menurut Umur (BB/U), sehingga dapat disimpulkan Ho diterima, tidak ada hubugan antara ASI Eksklusif dengan Berat Badan Menurut Umur (BB/U).

Hasil penelitian ini sejalan dengan penelitian yang dilakukan ginanti (2015) yang menyatakan bahwa bahwa tidak ada hubungan antara praktik pemberian Air Susu Ibu (ASI) dengan status gizi bayi dengan nilai $\mathrm{p}>0,05 .{ }^{8}$ Hal tersebut juga sesuai dengan penelitian yang dilakukan oleh Susanty, dkk. (2012) yang menunjukkan bahwa tidak ada hubungan antara pemberian ASI eksklusif dengan status gizi, artinya anak usia 6-24 bulan yang mendapatkan dan yang tidak mendapatkan ASI eksklusif memiliki peluang yang sama untuk menderita gizi buruk. ${ }^{3}$

Sebagian besar 92,6\% status pekerjaan ibu adalah ibu tidak bekerja (Ibu Rumah Tangga) dan sisanya 7,4\% merupakan ibu bekerja. Ibu yang tidak bekerja diharapkan ibu mempunyai waktu lebih banyak untuk dapat memperhatikan gizi anaknya dibanding ibu yang memiliki pekerjaan. ${ }^{9}$ Sebagian besar $71,3 \%$ status gizi anak merupakan anak dengan gizi normal dan sisanya 23,1\% merupakan gizi kurang, 5,6\% merupakan gizi buruk. Masih ditemukannya anak dengan gizi kurang dan gizi buruk dikarenakan berbagai faktor diantaranya sakit bulan yang lalu anak menderita sakit dan tidak lengkapnya pemberian imunisasi.

Sebagian besar baduta dalam penelitian ini telah mendapatkan imunisasi untuk terlindung dari penyakit atau dapat dikatakan dalam keadaan sehat sehingga hampir keseluruhan bayi mengalami status gizi yang baik. Dari hasil penelitian di atas memperlihatkan bahwa sebagian besar bayi yang diberi ASI secara Eksklusif, masih banyak diantaranya yang menderita gizi kurang bahkan bisa jadi buruk. Memburuknya gizi anak dapat terjadi oleh berbagai faktor seperti keadaan gizi ibu saat hamil, ibu yang jarak kehamilan sangat dekat juga dapat terjadi akibat ketidaktahuan ibu mengenai cara-cara pemberian ASI kepada anaknya, kurangnya pengertian dan pengetahuan ibu tentang manfaat ASI dan menyusui menyebabkan ibu ibu mudah terpengaruh dan beralih kepada susu botol (susu formula). Disamping itu juga sikap sementara penanggung jawab ruang bersalin dan perawatan dirumah sakit, rumah bersalin yang langsung memberikan susu botol pada bayi baru lahir ataupun tidak mau mengusahakan agar ibu mampu memberikan ASI kepada bayinya. 
Ibu yang tidak memberikan ASI eksklusif, memberikan makanan/minuman lain pada bayinya seperti air putih dan susu formula, waktu pemberian makanan/minuman selain ASI bervariasi, ada yang memberikan segera setelah lahir saat ASI belum keluar dan ada yang memberikan pada umur bayi 1 bulan dan 2 bulan.

\section{Hubungan Pemberian ASI Eksklusif dengan Panjang Badan Menurut Umur (PB/U)}

Berdasarkan Tabel 6, dari 71 baduta yang mendapatkan ASI Eksklusif, terdapat 15 baduta $(21,1 \%)$ yang berstatus gizi sangat pendek, 13 baduta (18,3\%) yang berstatus gizi pendek, 41 baduta $(57,8 \%)$ yang berstatus gizi normal, dan 2 baduta $(2,8 \%)$ yang berstatus gizi tinggi. Sedangkan yang tidak mendapatkan ASI Eksklusif sebanyak 37 baduta. Terdapat 6 baduta $(16,2 \%)$ yang berstatus gizi sangat pendek, 8 baduta $(21,6 \%)$ yang berstatus gizi pendek, 22 baduta $(59,5 \%)$ berstatus gizi normal, dan 1 baduta $(2,7 \%)$ yang berstatus gizi tinggi.

Berdasarkan hasil uji statistik Chi-Square diperoleh nilai p-value $=0,929(p<0,05)$ yang berarti tidak terdapat hubungan antara ASI Eksklusif dengan Panjang Badan Menurut Umur (PB/U), sehingga dapat disimpulkan Ho diterima, tidak ada hubungan antara ASI Eksklusif dengan Panjang Badan Menurut Umur (PB/U).

Hasil penelitian ini sejalan dengan penelitian yang dilakukan Cindy (2017) yang menyatakan bahwa diperoleh nilai $\mathrm{p}=0,601$ sehingga tidak terdapat hubungan antara pemberian ASI eksklusif dengan anak usia 6-24 bulan berdasarkan indeks antropometri $\mathrm{PB} / \mathrm{U}^{10}$ Menurut penelitian Indrawati (2016), ditemukan 3 responden yang diberikan ASI eksklusif dengan status gizi sangat pendek memiliki riwayat BBLR dimana berat badan lahir kurang akan mempengaruhi pertumbuhan anak selanjutnya termasuk tinggi badan anak. Selain itu, 2 diantaranya ibu memiliki riwayat KEK saat hamil sehingga kebutuhan zat gizi dalam kandungan tidak cukup dan berpengaruh terhadap pertumbuhan selanjutnya dan berisiko mengalami stunting. ${ }^{11}$

Penelitian ini sejalan dengan penelitian Novania (2016) yang dilakukan di desa Batu 12 Kecamatan Dolok Masihul Sumatera Utara bahwa tidak terdapat hubungan antara pemberian ASI eksklusif dengan status gizi indikator PB/U dengan value $(0,361) .{ }^{12}$ Upaya intervensi yang dapat dilakukan adalah memperbaiki gizi dan kesehatan ibu hamil, setiap ibu hamil perlu mendapat tablet tambahan darah, bayi dan anak memperoleh kapsul vitamin A, imunisasi dasar lengkap, memantau pertumbuhan balita di Posyandu merupakan upaya yang sangat strategis untuk mendeteksi dini terjadinya gangguan pertumbuhan, dan menerapkan perilaku hidup bersih dan sehat dalam keluarga. ${ }^{13}$

Sebagian besar tingkat pendidikan ibu tergolong rendah (tamat SD) yaitu sebesar $38 \%$. Penelitian Ramli et al di Maluku (2009) menemukan bahwa pendidikan ibu berhubungan signifikan dengan kejadian stunting pada balita. Hal ini dapat disebabkan karena peran pengasuhan lebih besar pada ibu daripada ayah. Ayah lebih banyak bekerja sehingga waktu yang dihabiskan dengan anak lebih sedikit (Ni'mah, 2015). ${ }^{14}$ Penelitian di Nepal oleh Tiwari, et al (2014) menunjukkan hal yang sama bahwa pendidikan ibu berhubungan dengan kejadian stunting balita. Rendahnya pendidikan ibu merupakan penyebab utama dari kejadian stunting pada anak sekolah dan remaja di Nigeria. Ibu yang berpendidikan lebih tinggi lebih memungkinkan untuk membuat keputusan yang akan meningkatkan gizi dan kesehatan anakanaknya. ${ }^{15}$ Tingkat pendidikan ibu juga menentukan kemudahan ibu dalam menyerap dan memahami pengetahuan gizi yang diperoleh. Dari kepentingan gizi keluarga, pendidikan 
diperlukan agar seseorang terutama ibu lebih tanggap terhadap adanya masalah gizi di dalam keluarga dan bisa mengambil tindakan secepatnya. ${ }^{16}$

\section{Hubungan Pemberian ASI Eksklusif dengan Berat Badan Menurut Panjang Badan (BB/PB)}

Berdasarkan Tabel 7, dari 71 baduta yang mendapatkan ASI Eksklusif, terdapat 4 baduta $(5,6 \%)$ yang berstatus gizi sangat kurus, 9 baduta $(12,7 \%)$ yang berstatus gizi kurus, 58 baduta $(81,7 \%)$ yang berstatus gizi normal, dan tidak didapatkan yang berstatus gizi gemuk. Sedangkan yang tidak mendapatkan ASI Eksklusif sebanyak 37 baduta. Terdapat 2 baduta $(5.4 \%)$ yang berstatus gizi sangat kurus, 3 baduta $(8,1 \%)$ yang berstatus gizi kurus, 28 baduta $(75,7 \%)$ berstatus gizi normal, dan 4 baduta $(10,8 \%)$ yang berstatus gizi gemuk.

Berdasarkan hasil uji statistik Chi-Square diperoleh nilai p-value $=0,041(p<0,05)$ yang berarti terdapat hubungan antara ASI Eksklusif dengan Berat Badan Menurut Panjang Badan (BB/PB), sehingga dapat disimpulkan Ho ditolak, ada hubugan antara ASI Eksklusif dengan Panjang Badan Menurut Umur (BB/PB).

Hasil penelitian ini sejalan dengan penelitian yang dilakukan Irot (2017) yang menyatakan bahwa nilai value $(0,021)$ lebih kecil dibandingkan dengan nilai $\alpha(0,05)$, artinya terdapat hubungan antara pemberian ASI eksklusif dengan status gizi anak usia $6-12$ bulan yang ditinjau dari berat badan menurut panjang badan di wilayah kerja Puskesmas Walantakan. ${ }^{17}$

Menurut data hasil penelitian di wilayah Desa Timbuseng lebih banyak anak yang mendapat ASI eksklusif yaitu sebesar 65,7\% dibandingkan dengan anak yang tidak diberikan ASI Eksklusif yaitu sebesar 34,3\%, karena lebih banyak ibu yang tidak berkerja/IRT dari pada ibu yang bekerja. Anak yang tidak diberi ASI eksklusif berdasarkan data hasil penelitian dikarenakan ibu bekerja dan menurut ibu ASI tidak cukup untuk anaknya. Ibu yang merasa ASInya tidak cukup kemudian memberikan bayinya susu formula, air putih, dan madu. Bayi yang sudah diberikan makanan/ minuman sebelum ASI ibunya keluar atau lancar kemudian diberi susu formula dan air putih.

Penelitian ini sejalan dengan penelitian Hasmini (2012) yang dilakukan di puskesmas Perawatan MKB Lompoe Kota Parepare bahwa terdapat hubungan antara pemberian ASI eksklusif dengan status gizi indikator BB/PB dengan value $(0,008) .{ }^{18}$

\section{KESIMPULAN}

Hasil penelitian menunjukkan bahwa tidak terdapat hubungan antara pemberian ASI Eksklusif dengan status gizi berdasarkan Berat Badan Menurut Umur $(p=0,457)$. Tidak terdapat hubungan antara pemberian ASI Eksklusif dengan status gizi berdasarkan Panjang Badan Menurut Umur ( $p=0,929)$. Terdapat hubungan pemberian ASI Eksklusif dengan status gizi Berdasarkan Berat Badan Menurut Panjang Badan $(p=0,041)$. Disarankan agar ibu berpartisipasi aktif dalam upaya perbaikan gizi dengan rajin membawa anak balitanya ke posyandu untuk memantau status gizi anak. Pada penelitian lebih lanjut perlu dengan sampel yang lebih banyak serta faktor variabel lain yang belum diteliti misalnya status gizi ibu serta faktor lain untuk memastikan ada perbedaan yang bermakna antara Pemberian ASI Eksklusif dengan status gizi bayi usia 6-24 bulan. 


\section{DAFTAR PUSTAKA}

1. Richard et. al. 2003. Nelson Textbook of Pediatrics 17th edition. W.B Saunders: Pennsylvania.

2. Siregar, Arifin. 2004. Pemberian ASI Eksklusif dan Faktor-faktor yang Mempengaruhinya. Dalam : http:/www./library.usu.ac.id. [Online] [Diakses pada tanggal 10 November 2019].

3. Susanty M, Kartika M, Hadju V dan Alharini S. 2012. Hubungan Pola Pemberian ASI dan MP ASI dengan Gizi Buruk pada Anak 6-24 Bulan di Kelurahan Pannampu Makassar. Jurnal Media Gizi Masyarakat Indonesia.

4. Dinas Kesehatan Kota Padang. 2007. Profil kesehatan tahun 2007. Padang; Dinkes Kota Padang.

5. Kemenkes RI. 2018. Riset Kesehatan Dasar; RISKESDAS. Jakarta : Balitbang Kemenkes RI.

6. Kementerian Kesehatan Republik Indonesia. 2019. Profil Kesehatan Indonesia Tahun 2018. Jakarta : Kementerian Kesehatan RI.

7. Dinas Kesehatan Provinsi Sulawesi Selatan. 2016. Profil Kesehatan Provinsi Sulawesi Selatan 2016. Makassar : Dinkes Provinsi Sulawesi Selatan.

8. Ginanti, nadyah, dkk. 2015. Hubungan Praktik Pemberian Air Susu Ibu (Asi) Dengan Status Gizi Bayi (Usia 0-6 Bulan) Di Wilayah Kerja Puskesmas Gayamsari Kota Semarang. Jurnal Kesehatan Masyarakat. Volume 3, Nomor 3.

9. Afrianto, Akhmad. 2012. Hubungan Pemberian Air Susu Ibu (ASI) dan Makanan Pendamping ASI (MP-ASI) dengan Status Gizi Anak Usia 4-24 Bulan (Studi Di Wilayah Kelurahan Wonodri Kecamatan Semarang Selatan Kota Semarang). Fakultas Kedokteran Universitas Muhammadiyah Semarang.

10. Cindy, dkk. 2017. Hubungan Pemberian Asi Eksklusif Dengan Status Gizi Anak Usia 624 Bulan Di Kelurahan Kakaskasen I Kecamatan Tomohon Utara. Fakultas Kesehatan Masyarakat Universitas Sam Ratulangi.

11. Indrawati S. 2016. Hubungan Pemberian ASI Eksklusif dengan Kejadian Stunting Pada Anak Usia 2-3 Tahun Di Desa Karangrejek Wonosari Gunungkidul. Naskah Publikasi. Universitas Aisyiyah Yogyakarta.

12. Novania A.S. 2016. Hubungan Antara Pengetahuan Ibu Terkait Pemberian ASI Eksklusif dan MPASI dengan Status Gizi Bayi di Desa Batu 12 Kecamatan Dolok Masihul, Sumatera Utara. Skripsi. Departemen Gizi Masyarakat Fakultas Ekologi Manusia Institut Pertanian Bogor.

13. Kementrian Kesehatan RI Pusat Data dan Informasi. 2016. Situasi Balita Pendek.

14. Ni'mah, Khoirun. 2015. Hubungan Faktor Karakteristik, Pola Konsumsi, dan Status Infeksi dengan Kejadian Stunting Balita. Skripsi. Universitas Airlangga.

15. Tiwari, R., Ausman, L.M., dan Agho, K.E. 2014. Determinant of Stunting and severe Stunting Among Under Fives: Evidence from the 2011 Nepal Demographic and Health Survey. BMC Pediatric 2014 14:239

16. Kurnia, Rizki. 2017. Hubungan Pendapatan Keluarga, Berat Lahir, Dan Panjang Lahir Dengan Kejadian Stunting Balita 24-59 Bulan Di Bangkalan. Jurnal Manajemen Kesehatan. Volume 3, Nomor 1. 
17. Irot, dkk. 2017. Hubungan Antara Pemberian Asi Ekslusif Dengan Status Gizi Bayi Usia 6-12 Bulan Di Wilayah Kerja Puskesmas Walantakan Kecamatan Langowan Utara Kabupaten Minahasa. Fakultas Kesehatan Masyarakat Universitas Sam Ratulangi.

18. Hasmini N. 2012. Hubungan Riwayat Pemberian ASI Ekskslusif dengan Status Gizi Bayi Umur 6 - 12 Bulan di Puskesmas Perawatan MKB Lompoe Kota Parepare Tahun 2012. Skripsi. Fakultas Kesehatan Masyarakat Universitas Indonesia. 